\title{
Cultura, Self e Autonomia: Bases para o Protagonismo Infantil
}

\author{
Sergio Fernandes Senna Pires ${ }^{1}$ \\ Universidade de Brasília \\ Câmara dos Deputados \\ Angela Uchoa Branco \\ Universidade de Brasília
}

\begin{abstract}
RESUMO - Neste artigo são discutidas as bases do protagonismo (ou participação) infantil na sociedade: cultura, construção do self e autonomia. São apresentados os principais fundamentos teóricos da abordagem sociocultural construtivista ao se discutir o self como sistema complexo e dinâmico, co-construído mediante a interação entre sujeito ativo e canalizações culturais. Diante das práticas culturais relacionadas à institucionalização da infância, analisam-se como crenças e valores podem contribuir para a participação infantil nos processos decisórios e para a superação das limitações atuais. Conclui-se que a abordagem co-construtivista, efetivamente, pode contribuir para a promoção do protagonismo infantil, visto que destaca as dimensões da cultura e do sujeito construtivo, aí implicadas.
\end{abstract}

Palavras-chave: self; autonomia; participação infantil; protagonismo infantil.

\section{Culture, Self and Autonomy: Paving the Road for Children's Participation}

\begin{abstract}
This article discusses the basic dimensions that may contribute to foster children participation in social change: culture, self-construction and autonomy. It presents theoretical concepts and principles of sociocultural constructivism related to self, here conceived as a complex and dynamic system resulting from interactions between active individual and cultural canalizations. Taking into account cultural practices related to the institutionalization of childhood, it analyzes how values and beliefs may contribute to children social participation in decision making processes, overcoming current limitations. It concludes that co-constructivism may indeed contribute to promote children social participation, since it emphasizes both culture and the constructive individual.
\end{abstract}

Keywords: self; autonomy; children participation.

Os estudos sobre os aspectos psicológicos a respeito da participação infantil nos processos decisórios consideram os elementos teóricos sobre a construção histórico-cultural da infância (e.g., Ariès, 1973/1978; Kramer, 2003; Kramer \& Leite, 1996), pois desvelam aspectos e processos fundamentais para a compreensão da construção de significados e das práticas sociais relacionadas às crianças. $\mathrm{O}$ destaque para a análise da institucionalização do cuidado com a criança e os pontos de vista dos diversos autores sobre os graus de autonomia e a conquista de uma efetiva participação infantil, em especial no ambiente escolar, indicam a necessidade de uma análise minuciosa e sistêmica dos processos envolvidos (Branco, 2003, 2006; Valsiner, 1989, 2007). A investigação do controle social exercido sobre as crianças revela o poder do Estado e da sociedade dos adultos sobre o desenvolvimento infantil e sua análise se constitui em importante elemento para o entendimento mais amplo de questões referentes à autonomia e à participação infantil nos processos decisórios.

Este artigo tem por objetivo discutir elementos do contexto sociocultural que influenciam na ação participativa das crianças em processos decisórios coletivos. Necessariamente, nossa argumentação se apóia em contribuições de diversos campos do saber como a História, a Sociologia, a Antropologia e o

1 Endereço: Câmara dos Deputados, Consultoria Legislativa, Gab. 23B, Anexo III, Palácio do Congresso Nacional. Brasília, DF. CEP 70160-900.E-mail: senna_pires@yahoo.com.br.
Direito, pois, de outra forma, não seria possível tratar com as diversas dimensões que são relevantes para a compreensão dos aspectos psicológicos do desenvolvimento humano.

A discussão abordará aspectos como autonomia, desenvolvimento moral, responsabilidade social, crenças, valores, práticas culturais e motivação, na qualidade de importantes dimensões para a compreensão do desenvolvimento e da promoção da participação infantil sob o ponto de vista da abordagem sociocultural construtivista.

\section{A Perspectiva Sociocultural Construtivista}

A abordagem teórica sociocultural construtivista, ou coconstrutivista, está baseada nas idéias de Mead, Baldwin, Vigotski e Piaget (Madureira \& Branco, 2005). Suas principais características são: (1) adoção de uma visão sistêmica; (2) contextualização do desenvolvimento na sociocultura; (3) ênfase no estudo dos processos de co-construção de significados; e (4) concepção do desenvolvimento humano que considere a atuação conjunta da canalização cultural e a intencionalidade do sujeito (e.g., Cole, 1992; Ford \& Lerner, 1992; Rogoff, 1993; Valsiner, 1987, 1989, 1994; Valsiner, Branco \& Dantas, 1997; Vigotski, 1934/2001; Werstch, 1991, 1998).

À dimensão cultural é dispensado um especial destaque, pois se considera que a produção simbólica fundamenta e constitui o pensamento (Valsiner, 2007; Vigotski, 1934/2001), 
caracterizando as ações humanas. As relações sociais se dão em diferentes contextos semióticos (simbólico-culturais), que são partilhados entre os integrantes de determinado grupo. Esses ambientes e condições culturais singulares participam da constituição das subjetividades em um processo que se estende ao longo de todo o ciclo de vida (Valsiner, 1989, 1994, 2007). É importante salientar que, ao enfatizar a dimensão coletiva da constituição da subjetividade em contextos semióticos, a perspectiva sociocultural construtivista não diminui o papel do indivíduo como agente ativo na construção, tanto da sua própria subjetividade, quanto do ambiente cultural coletivamente estabelecido (Branco, 2006; Valsiner, 1994). Ainda que a cultura atue como organizadora dos espaços de construção de significados ao longo do tempo, cada pessoa possui possibilidades e certa flexibilidade para conduzir e constituir, de forma intencional e não-intencional, os seus processos de internalização e externalização e de ação no mundo.

A abordagem sociocultural construtivista também se interessa pela microgênese dos processos psicológicos e pelos processos que estão implicados na ontogênese da motivação, dos sistemas pessoais de valores, das orientações para crenças e objetivos. Além disso, é de suma importância compreender como atuam os processos desenvolvimentais em contextos culturais estruturados específicos e como se constituem sujeito e subjetividade em relação aos contextos culturais.

Segundo essa perspectiva, o ser humano se constitui como sujeito de forma interativa e dinâmica, assumindo um papel ativo e participativo nessa construção. Nessas condições, os sujeitos conduzem suas negociações semióticas nas interações com outras pessoas, em variados contextos. Mesmo em cenários extremos, bastante autoritários e desfavoráveis à plena negociação de significados, como os descritos nas Teorias de Reprodução Cultural e Violência Simbólica (e.g., Althusser, 1985/2007; Bourdieu, 1989, 1967/1998; Bourdieu \& Passeron, 1970/1975), a possibilidade de ação ativa dos sujeitos não é anulada. A noção de reprodução como uma cópia em verdadeira grandeza, entendida como a imagem refletida em um espelho plano, não encontra sustentação teórica sob o ponto de vista sociocultural construtivista no que se refere à construção de significados e à internalização e externalização de crenças e valores.

Os processos de comunicação e metacomunicação ganham particular destaque no contexto das interações sociais. Desempenham um papel central na ontogênese dos valores, os quais são negociados em meio às práticas culturais e ao longo da dinâmica das internalizações e externalizações que promovem a mútua constituição sujeito-sociedade (Elias, 1987/1994). Aos padrões de interação ocorridos face a face ainda podem ser acrescidos todos os que, utilizando-se dos meios de comunicação tecnologicamente disponíveis, estabeleçam momentos específicos de contato entre seres humanos e/ou sua produção simbólica.

A metacomunicação, compreendida como um modulador da comunicação, assume um papel preponderante na constituição da dimensão motivacional. Refere-se às mensagens inseridas sobre o próprio processo de comunicação, presentes nas interações e que permeiam as relações humanas (e.g., Branco \& Valsiner, 2004; Watzlawick, Beavin \& Jackson, 1967). Assume um papel essencial na medida em que contextualiza e direciona a interpretação dos significados co-construídos nos processos de comunicação que se dão nas interações sociais, colaborando, assim, de forma fundamental, para o desenvolvimento do self e da qualidade das interações e relações humanas.

Por meio do estudo das interações sociais e processos comunicativos, é possível, portanto, entender que nível de liberdade e responsabilidade cada sujeito pode alcançar em determinados contextos culturalmente estruturados. No caso da promoção da autonomia e da participação infantil, esse aspecto é fundamental para que se analise a regulação das práticas sociais por valores que promovam a competição e o individualismo frente à possibilidade de ações protagônicas por parte das crianças na direção contrária a esses valores. Esse protagonismo exige uma disposição cooperativa e de colaboração entre adultos e crianças, tendo em vista a transformação ou mudança criativa de aspectos da sociocultura que se deseja superar.

\section{Desenvolvimento Humano e Cultura}

Ao introduzir um conceito tão polissêmico e complexo quanto cultura, é necessário iniciar a argumentação por uma das características que distingue o ser humano de todos os outros animais: a intencionalidade. Tanto Vigotski (1934/2001) quanto Bruner (1990/1997) argumentam que o ser humano deve ser compreendido a partir de suas intenções. Para esses autores, a cultura organiza a operação simbólica humana, emprestando significado às ações e aos estados emocionais, relacionando-os a um sistema interpretativo mais geral, compartilhado por um grupo de pessoas. É a participação nesses sistemas semióticos que proporciona a possibilidade da criação de inúmeras configurações simbólicas que acabam por terem a capacidade de se tornarem modos de vida através das ações humanas.

Segundo Geertz (1973/1978), sob uma ótica antropológica, a cultura deve ser compreendida como conjuntos imbricados de significados, que têm a finalidade de orientar o que ocorre nas mais diversas dimensões constituintes dos seres humanos. São guias simbólicos, muito mais do que padrões concretos de comportamentos, tradições ou hábitos. Sob o ponto de vista psicológico, interessam, particularmente, os estudos realizados a partir da Psicologia Cultural (Bruner, 1990/1997; Shweder, 1991; Tomasello, 1999; Valsiner, 2000; Valsiner \& Van der Veer, 2000; Werstch, 1998), que investigam o modo pelo qual as tradições e as práticas sociais geram, regulam, expressam e transformam sujeito e sociedade. Entretanto, a abordagem sociocultural construtivista realiza um esforço teórico para não dicotomizar o sujeito e a cultura. O conceito de separação inclusiva significa a preservação da diferença entre as categorias teóricas sem, no entanto, determinar o seu isolamento analítico, o que é essencial quando se assume a dimensão complexa e sistêmica das categorias psicológicas (Valsiner, 2007; Valsiner \& Cairns, 1992)

As canalizações culturais (Valsiner, 1989, 2007) assumem fundamental importância e se constituem nos processos que disponibilizam significados e sugestões culturais a um indivíduo, de forma que este possa se inserir e participar no universo de valores e significados das culturas pelas quais transita (Branco, 1993, 2006; Valsiner, 1987). Porém, 
é fundamental compreender que a canalização cultural é complementada pelo aspecto construtivista inerente à participação ativa do sujeito nesse processo, e muitas das teorias sociogenéticas atuais não enfatizam o papel ativo do sujeito na internalização e alteração de referenciais interpretativos. A proposta da abordagem sociocultural construtivista sobre o desenvolvimento da criança procura, assim, destacar a singularidade do sujeito humano e, ao mesmo tempo, o fato de que este sujeito está indissociavelmente relacionado às demais pessoas e aos referenciais simbólicos presentes nos contextos culturais dos quais participa (Valsiner 1987, 2000). Sob esse ponto de vista, a internalização ou a apropriação pessoal e criativa das sugestões socioculturais é como uma síntese dialética entre elementos pessoais e coletivos (Valsiner, 2007; Wertsch, 1998).

Para uma compreensão mais aprofundada dos processos de internalização ou apropriação, no entanto, é necessário considerar a dimensão da afetividade e dos processos motivacionais nos estudos sobre as relações pessoa-contextos culturais. Apesar de ser um tema tão central e significativo para o entendimento da motivação e ação humanas, muito falta ser investigado sobre as dimensões afetiva e emocional. Argumentando sobre a dificuldade em se abordar o tema, González Rey (1999/2002) afirma:

Um dos problemas que o estudo psicológico das emoções tem enfrentado é a incapacidade para transmitir de uma compreensão biológica da psiquê para uma compreensão cultural, subjetiva, dentro da qual as emoções não aparecem só como momento de expressões da pessoa ante estados biológicos, mas sim associadas a estados subjetivos. Esse trânsito exige o desenvolvimento de um aparato de categorias que nos permitam superar o racionalismo subjacente nas diferentes representações da subjetividade que pretendem reduzir esta a registros provenientes da significação (p. 243).

Branco (2006) argumenta que existe uma relação de constituição dialética entre as categorias cultura e subjetividade, e essas são fortemente moduladas pela afetividade. Uma vez que a motivação humana está diretamente relacionada com os processos de socialização, então a internalização de crenças e valores (princípios organizadores do pensamento, da ação e constituintes dos referenciais interpretativos) se torna fundamental para a expressão dos indivíduos por meio das práticas culturais. Sob esse ponto de vista, é no contexto das práticas diárias e em seus microssistemas que os indivíduos constituem a subjetividade em meio à polifonia e à multidimensionalidade da vivência humana e da produção dos significados. Considerar a afetividade como importante constituinte do desenvolvimento é fundamental para a compreensão dos processos nos quais ocorrem a organização da moralidade e a internalização de crenças e valores, como veremos adiante.

\section{Self e Cultura}

Sob o ponto de vista psicológico, é necessário aprofundar o estudo da formação da subjetividade na direção da compreensão dos motivos e significados que orientam as pessoas em suas relações umas com as outras. Segundo
Valsiner (2007), a cultura é o elemento que integra o sistema de funções psicológicas desenvolvidas pelo indivíduo na organização histórica de seu grupo social, por meio dos processos de interação social, canalização e trocas, fazendo uso dos recursos e dos instrumentos semióticos co-construídos. Assim, temos como pressuposto o fato de que a cultura oferece, aos indivíduos, significados historicamente localizados, estabelecendo limites e possibilidades para as suas ações. No entanto, cada pessoa, ao reconstruir esses significados, ao criar suas versões pessoais e externalizá-las, pode superar os supostos limites, agindo de acordo com suas próprias orientações para objetivos e crenças, que podem ser distintas daquelas que predominam nos contextos socioculturais em que a pessoa está inserida.

A concepção sociocultural construtivista destaca a importância dos processos semióticos e da utilização de ferramentas culturais na construção do sujeito (self) e da subjetividade. Ênfase especial é dada aos aspectos dinâmicos e processuais da construção da subjetividade de forma descentrada, constituída e transformada continuamente nos sistemas culturais que a envolvem, em articulação com o caráter ativo do sujeito nas construções de si e da sociocultura. Estudos contemporâneos sustentam a existência dessa dinâmica entre sujeito e cultura e definem a subjetividade como uma instância organizadora do ser humano (Bruner, 1987/1998; Hermans, 1996; Hermans, Kempen \& Van Loon, 1992; McLaren \& Giroux, 2000; Sampson, 1985; Valsiner, 2000).

De forma geral, as designações que procuram significar a subjetividade remetem à organização de diversas dimensões, na medida em que essa se desenvolve de forma a incluir um complexo e dinâmico sistema de autopercepção, autoconceito, auto-imagem, auto-estima, consciência de si e diferenciação em relação aos outros seres e ambientes (Gone, Miler \& Rappaport, 1999). Esse aspecto é relevante, pois existe uma grande divergência teórica quando se trata da construção da subjetividade, variando de uma perspectiva mais centrada na elaboração por meio de explicações intrapsicológicas, para concepções mais pautadas na definição a partir de sua dimensão social. Uma visão mais sistêmica do fenômeno relacionado à questão da subjetividade deve incluir, portanto, as diversas dimensões relacionadas à constituição do self (Cushman, 1990; Hermans, 1996; Hermans, Kempen \& Van Loon 1992; Sampson 1985; Valsiner, 1998, 2000).

Nessa mesma busca por respostas, procurando enfatizar o papel ativo do sujeito e a importância da cultura coletiva na construção da subjetividade, Valsiner $(1998,2007)$ discorre sobre a influência da teoria social de Durkheim e explica que a pessoa faz uso de representações coletivas para construir seu próprio sistema de significados durante o seu desenvolvimento. Porém, ao contrário do determinismo social sobre o indivíduo preconizado por Durkheim, Valsiner (2007) propõe um modelo teórico para explicar o desenvolvimento do self em uma perspectiva dialógica 'pessoa-sociedade', constituindo-se a pessoa em um processo dinâmico e fluído que prevê a ação conjunta de auto-organização e inovação. Estruturação e criação são movimentos que ocorrem de forma simultânea. Os diálogos são necessários para a emergência de fenômenos mentais novos e coerentes com a experiência humana. Apesar desta ser multifacetada e eminentemente fluída, o ser em desenvolvimento busca incessantemente 
por coerência e organização, ainda que de forma transitória. Assim, o self, aqui entendido como um sistema dialógico e dinâmico que envolve sujeito e subjetividade, apresenta-se com fronteiras flexíveis entre as dimensões intra e interpsicológicas e se desenvolve nas interações interpessoais (reais ou imaginárias), colaborando para a construção de novos significados pessoais e coletivos ao longo de sua própria organização e desenvolvimento.

Partindo de uma abordagem sistêmica, Valsiner (1998) pressupõe a auto-agência no processo de co-construção do significado. A partir de diversas reflexões, propõe um modelo bidirecional, co-construtivista de desenvolvimento, no qual instrumentos de mediação semiótica são percebidos como guias sociais, que permitem a construção pessoal de significados, ao mesmo tempo em que possibilitam a modificação das práticas e bens simbólicos oferecidos pela cultura coletiva.

Tal modelo propõe que o desenvolvimento é, simultaneamente, guiado pela dimensão social e pelas várias posições de self em ação, ou self dialógico (Hermans, 2001), que também se caracteriza como um sistema complexo e dinâmico. Esse processo caracteriza-se pela construção de instrumentos de mediação semiótica - estruturas de significado - que o sujeito desenvolve para compreender e agir nos ambientes. $\mathrm{O}$ desenvolvimento resulta da relação entre os mundos intra e interpsicológicos, por meio de contínuos processos de negociação (internalizações/externalizações) entre as diferentes posições.

Esses processos de negociação entre o sujeito e as culturas não ocorrem de forma simétrica, como analisa Oppenheimer (2001), quando se propõe a contribuir para esclarecer a singularidade do self na emergência de novidades. Considera, por exemplo, a importância das forças socioculturais mais amplas sobre o self, investigando a influência de contextos culturais predominantemente individualistas sobre o desenvolvimento de um self mais individualista, independente e competitivo. Da mesma maneira, influências socioculturais mais coletivistas orientariam a construção do self e da cultura pessoal no sentido do coletivismo e da cooperação (Branco, 2003). Essas pesquisas indicam que a influência da sociocultura sobre o sujeito está longe de ser mero fator modulador de pequena magnitude. Apesar do grau de liberdade que o sujeito dispõe para a construção de suas versões pessoais, a sociocultura pode influenciar, de forma decisiva, o conteúdo dessas versões.

A partir desses referenciais teóricos, verifica-se que a cultura coletiva oferece sugestões e orientações que são apropriadas pelos indivíduos em simultâneos processos de internalização e externalização, com o que podem participar da transformação das mesmas sugestões anteriormente disponíveis, pela criação e externalização de novos significados. A fim de situar a posição do sujeito em meio à correlação de forças, é necessário admitir que, apesar da ênfase na capacidade do sujeito em exercer um papel ativo na construção de sua cultura pessoal, a canalização cultural pode ocorrer de variadas formas. Um cenário possível é aquele em que as sugestões culturais sejam tão redundantes, e convincentes no campo afetivo, que resultem em uma forte canalização. Em tal cenário, é possível que valores como o individualismo, por exemplo, tal como observado na cultura ocidental por Sampson (1985) e Cushman (1990), venham a predominar sobre orientações de caráter coletivista e/ou pró-social (Branco, 2003).

Detalhando a ação organizadora dos valores e ao discutir questões relacionadas aos processos de alienação e persuasão típicos da sociedade ocidental contemporânea, Sampson (1985) afirma que valores como liberdade, responsabilidade e produtividade, promovidos em função do individualismo, são formas de apoio às instituições que sustentam a sociedade capitalista, uma vez que esta subjuga o grupo em detrimento de um self individualista. Em sua análise, o autor acredita que a concepção de individualismo não é, necessariamente, a que prevalece na organização de muitas sociedades, mas ainda assim é o modelo de self mais disseminado no mundo ocidental em função da dominação cultural e prevalência das opiniões e valores individualistas (Branco, 2003) promovidos pelo modelo econômico capitalista, que é predominante.

Nas condições apresentadas por Sampson (1985), a subjetividade se constrói por meio da ilusão da autonomia. Os indivíduos se concebem livres, no entanto é como se sua subjetividade fosse construída por meio de uma autopersuasão e adoção dos referenciais simbólicos que são amplamente disponibilizados (pela cultura coletiva) por meio de uma forte canalização cultural que se utiliza de aparelhos ideológicos (Althusser, 1985/2007). Esse tipo de análise mostra que não é possível separar o desenvolvimento moral das demais dimensões do desenvolvimento humano e dos contextos histórico-culturais.

\section{Autonomia, Moralidade e Desenvolvimento Humano}

A ênfase que a abordagem sociocultural construtivista empresta ao papel ativo do sujeito na construção simultânea da subjetividade e da sociocultura traz ao primeiro plano o estudo teórico da autonomia e da moralidade no desenvolvimento. Para Piaget (1932/1994), a autonomia representa a condição alcançada pela criança em desenvolvimento quando esta considera os vários fatores relacionados à intencionalidade, à dimensão da responsabilidade social e à independência do julgamento moral, antes heterônomo. $\mathrm{O}$ conceito, portanto, encontra-se intimamente ligado à questão da moralidade (consideração e respeito à alteridade), bem como à questão da iniciativa de ação associada à relativa independência na avaliação do que seja certo ou errado em determinado contexto.

Martins e Branco (2001) explicam que o desenvolvimento ético-moral, no último século, tem sido objeto de inúmeros estudos (eg., Bandura, 1991; Bandura \& Walters, 1959; Freud, 1905; Kohlberg, 1976, 1984; Piaget, 1932/1994). Uma das abordagens mais valorizadas pela comunidade científica é a de Kohlberg (1981), que amplia as contribuições de Piaget sobre a questão. De origem cognitivo-estruturalista, a proposta de Kolhberg rejeita o relativismo ético e baseiase em princípios morais universais, sendo que a justiça é o critério principal de regulação moral. Enfatiza o componente cognitivo da moralidade, o raciocínio moral, e estabelece uma 
hierarquização composta por de seis níveis de moralidade: dois categorizados como típicos do estágio pré-convencional, dois do convencional e dois do pós-convencional. Um dos avanços oferecidos por essa proposta é a assincronia entre os estágios e a idade cronológica.

Embora o mérito da teoria cognitiva do desenvolvimento moral seja incontestável, seus críticos apontam aspectos controversos: (1) a universalidade dos estágios morais; (2) a falta de consideração da influência do contexto sociocultural; e (3) não levar em conta a afetividade nos processos de significação relacionados à moralidade. As críticas indicam, assim, as limitações do modelo cognitivo-estruturalista, limitações essas que abordagens socioculturais procuram superar (Shweder \& Much, 1987). A perspectiva sociocultural construtivista critica, sobretudo, a desconsideração das teorias baseadas no raciocínio moral (com seus estágios universais) das relações entre o raciocínio moral (cognição) e as vivências afetivas dos sujeitos, consideradas sob o ponto de vista holístico, e a partir da valorização da diversidade cultural (Cole, 1988, 1992). Uma vez que o estudo da produção dos significados está na base da abordagem, dá-se importância aos aspectos que articulam a comunicação humana praticada em contextos culturais específicos para a compreensão da forma como diversas dimensões se articulam para a configuração e reconfiguração de um sistema simbólico ético-moral.

O enfoque co-construtivista procura compreender o desenvolvimento ético-moral a partir da experiência dos sujeitos. Sob essa ótica, a experiência moral e ética das pessoas se desdobra em diversas dimensões, entre elas: (1) cognitiva; (2) afetiva; (3) intencionalidade. É na articulação dessas dimensões, entre outras, quando entendidas a partir dos próprios referenciais culturais do sujeito e ligadas aos seus processos de mediação simbólica, que se pode chegar a alguma conclusão a respeito do desenvolvimento moral (Branco, 2006).

Em especial, diante da questão universalismo versus relativismo, é necessário um aprofundamento da análise, pois, apesar de passíveis de variação, alguns princípios podem ser considerados gerais o suficiente para serem válidos transculturalmente nos grupos humanos. É o caso do respeito à vida e dos direitos humanos fundamentais, por exemplo. Tais princípios se relacionam, porém, com um conjunto muito mais amplo de crenças e valores do ser humano sobre si, sobre os 'outros' e sobre a vida em geral que estão profundamente impregnados da cultura específica (Shweder \& Much, 1987).

Um aspecto teórico importante a ser destacado no estudo do caráter sociogenético da moralidade relaciona-se à ontogênese das crenças e valores. Quando um ser humano nasce, encontra uma cultura coletiva cuja configuração é dinâmica, mas cujos conteúdos se sustentam em bases históricas e afetivas, em termos de valores, padrões típicos de relacionamento e referenciais interpretativos. A anterioridade dos padrões culturais, no entanto, não garante nenhum determinismo, visto que a canalização cultural atua de forma simultânea com a indeterminação, que está na matriz da emergência de novos padrões, crenças e valores nos contextos específicos (Branco, 2006; Madureira \& Branco, 2005; Valsiner, 1987, 2007). Coerentemente com os princípios da canalização cultural, tanto fortes sugestões culturais quanto indeterminismos colaboram para configuração de um sem número de subjetividades diferentes (Fogel, Lyra \& Valsiner, 1997). A canalização cultural é, portanto, um dos processos mais importantes na sociogênese de crenças e valores, porém ela não é fator determinante das características e do curso da vida dos seres humanos.

\section{Canalização Cultural, Escola e Protagonismo Infantil}

Considerando o contexto da construção da subjetividade anteriormente exposto, quais são os critérios (idéias, valores, padrões) que importam ser promovidos para que as crianças tenham efetiva participação nos processos decisórios? Sob o ponto de vista psicológico, alguns autores (e.g., Gone, Miler \& Rappaport, 1999) argumentam que desenvolver a consciência de si, a reflexividade, a intencionalidade e a capacidade para realizar julgamentos de valor, associadas a uma condição de autonomia, é condição fundamental para a ocorrência de iniciativas e práticas simbólicas reguladas por metas compartilhadas e pelo compromisso de transformação social.

Nesse sentido, a escolarização e sua institucionalização é o contexto propício para que as crianças possam exercer sua máxima participação, pois passam, no mínimo, cinco horas diárias na escola durante os nove anos obrigatórios do ensino no Brasil. No entanto, também é propício para a condução de estratégias de disciplina e imposição de significados. Um dos principais efeitos observáveis do processo de institucionalização da escolarização infantil foi a nítida separação do "mundo das crianças" do "mundo dos adultos", com ênfase na utilização do critério cronológico para a caracterização precisa da passagem de um momento a outro do ciclo de vida. Além disso, quando, coletivamente, se admitiu que a criança não é um ser maduro para a vida, que é necessário submetêla a um regime especial antes de permitir o seu ingresso na vida adulta, deu-se início ao conseqüente prolongamento da infância em sincronia com a duração da escolarização obrigatória. A conjugação de tais condições não seria uma forma de canalizar o prolongamento do período em que prevalece a concepção de inaptidão e incompletude da criança?

Não é possível analisar a questão do protagonismo (ou participação) infantil sem considerar as relações de poder em que adultos e crianças estão envolvidos. Interessam, especialmente, as relações de poder que se estabelecem nos ambientes escolares e que poderão servir de ambiente para a promoção da participação infantil, ou seja, o envolvimento ativo nos processos decisórios coletivos de uma parcela da população que, historicamente, por ter menor idade, foi segregada e afastada das práticas decisórias referentes à organização e dinâmica da vida social (Ariès, 1973/1978; Kramer, 2003; Kramer \& Leite, 1996).

Apenas a título de exemplo, recuperamos a argumentação das Teorias de Reprodução Cultural (e.g., Bourdieu \& Passeron, 1970/1975) sobre a ação e autoridade pedagógicas para destacar os elementos das dinâmicas de internalizações e externalizações de crenças e valores em um cenário de violência simbólica (outros cenários teóricos, de reprodução ou resistência, podem ser utilizados para análises desse tipo). Sob o ponto de vista psicológico, essas teorias discutem os aspectos motivacionais e emocionais necessários para que pos- 
síveis resistências por parte do grupo cultural a ser dominado possam ser minimizadas, maximizando a probabilidade de adesão às orientações culturais provenientes de tal autoridade. A partir da ênfase que tanto Althusser (1985/2007), quanto Bourdieu (1989), por exemplo, emprestam aos processos comunicativos persuasivos - principalmente quanto ao sigilo necessário para que um esquema de violência simbólica e reprodução cultural sejam bem sucedidos — pode-se verificar que os autores admitem que os sujeitos também resistem e não reagem de forma passiva e totalmente alienada aos esquemas de imposição cultural.

Uma boa indicação da plausibilidade desse raciocínio é a pressuposição da extrema importância da comunicação verdadeiramente dialógica para a ocorrência de um cenário de reprodução cultural, segundo Bourdieu e Passeron (1970/1975). Estes autores destacam a dimensão dialógica como necessária para a reprodução, já que a dialogia, para ele, por um lado implica em considerar a subjetividade do ser humano (pensamentos, emoções etc.), ao mesmo tempo em que ressalta o contexto social como elemento central da dimensão dialógica. Em outras palavras, em um contexto de reprodução persuasiva no qual se deseja impor determinados valores, é extremamente produtivo conquistar o self de cada um por meio de sugestões culturais racional e afetivamente convincentes, associadas à ação de algum tipo de aparelho ideológico (Althusser, 1985/2007).

Diversos estudos concluem que a escola pode ser um eficaz veículo para a difusão de valores no contexto de sugestões culturais sobrepostas em diversos níveis (Valsiner, 1989). Quando diversas instituições difundem as mesmas orientações, reforçam suas influências sobre o sujeito. Ao inundarem o ambiente cultural com sugestões semelhantes, contribuem para uma forte canalização no sentido de que as pessoas internalizem/externalizem os referenciais e valores propagados. Esse modo de operar não garante, porém, que as internalizações/externalizações sejam uniformes, mas aumenta, em muito, a probabilidade que haja semelhanças desenvolvimentais, principalmente se consideradas as ações do grupo como um todo.

\section{Considerações Finais}

No contexto teórico aqui abordado, promover a participação infantil significa investir na autonomia e na capacidade de autoconstrução e auto-regulação de subjetividades. Promover a participação infantil não é incentivar o surgimento de pessoas rebeldes e desordeiras e nem significa a submissão incondicional dos adultos à vontade das crianças. Raciocinar dessa forma seria apenas inverter a situação entre oprimidos e opressores sem que houvesse qualquer ganho para a coletividade. Promover a participação é experimentar um sistema complexo de interações que se configura em torno da iniciativa, das responsabilidades compartilhadas e, principalmente, do compromisso que grupos de pessoas, crianças e adultos, podem assumir durante a condução do processo decisório da realização das ações de um determinado projeto.

No entanto, é necessário notar que os valores que organizaram a separação do mundo entre crianças e adultos não facilitam esse tipo de configuração e compartilhamento de responsabilidade e compromissos. Atualmente, existem abundantes sugestões culturais acerca das vantagens e da necessidade imaginária do exercício do individualismo e da competição, o que cria uma ilusão de independência e auto-suficiência, na qual o próprio self se bastaria (Cushman, 1990). Dessa forma, a construção da subjetividade pode se tornar refém das fortes sugestões simbólicas, e isso resultar em um self que se acredita soberano e independente. Assumir a existência de uma construção simbólica bidirecional, entretanto, não garante proteção contra a forte canalização cultural. Assim sendo, há que se empreender ações de participação de diferentes naturezas e mobilizar recursos diversos que, de fato, impliquem mudanças qualitativas significativas do status quo das instituições educacionais. Uma delas é o estímulo e a abertura concreta de possibilidades de participação ativa por parte das crianças nos processos decisórios. Ainda que em um contexto hostil caracterizado por uma cultura opressiva, a participação infantil representa um grande potencial para a realização de transformações socioculturais importantes. Afinal, a dinâmica social nos dias atuais se caracteriza pela disponibilização contínua de diversos referenciais simbólicos, geradores de uma multiplicidade de orientações para crenças e objetivos. É a própria presença dessa pluralidade que, ao se contrapor à hegemonia, abre espaço para mudanças e transformações fundamentais à sociedade.

\section{Referências}

Althusser, L. (2007). Aparelhos ideológicos de estado: Nota sobre os aparelhos ideológicos de estado. (W. J. Evangelista \& M.L.V de Castro, Trad.) Rio de Janeiro: Graal. (Trabalho original publicado em 1985)

Ariès, P. (1978). História social da criança e da família. (D. Flaksman, Trad.) Rio de Janeiro: LTC. (Trabalho original publicado em 1973)

Bourdieu, P. (1989). O poder simbólico. (F. Tomaz, Trad.) Lisboa: Difel. (Trabalho original publicado em 1989)

Bourdieu, P. (1998). Economia das trocas simbólicas. (S. Miceli, Trad.) São Paulo: Perspectiva. (Trabalho original publicado em 1967)

Bourdieu, P. \& Passeron, J. C. (1975). A reprodução. (R. Bairão, Trad.) Rio de Janeiro: Francisco Alves. (Trabalho original publicado em 1970)

Branco, A. U. (1993). Sociogênese e canalização cultural: contribuições à analise do contexto das salas de aula. Temas de Psicologia, 3, 9-18.

Branco, A. U. (2003). Social development in social contexts: Cooperative and competitive interation patterns in peer interactions. Em J. Valsiner \& K. J. Conolly (Orgs.). Handbook of developmental psychology (pp. 238-256). London: Sage.

Branco, A. U. (2006). Crenças e práticas culturais: co-construção e ontogênese de valores sociais. Revista Pro-Posições, 17, 139-155.

Branco, A. U. \& Valsiner, J. (2004). Communication and metacommunication in human development. Greenwich: Information Age Publishing.

Bruner, J. (1997). Atos de significação. (S. Costa, Trad.) Porto Alegre: ArtMed. (Trabalho original publicado em 1990)

Bruner, J. (1998). Realidade mental, mundos possiveis. ( M.A.G. Domingues, Trad.) Porto Alegre: ArtMed. (Trabalho original publicado em 1987) 
Cole, M. (1988). Cross-cultural psychology in the sociohistorical tradition. Human Development, 31, 137-157.

Cole, M. (1992). Culture in development. Em M.H. Bornstein \& M.E. Lamb (Orgs.), Developmental Psychology: An advanced textbook (pp. 731-788). Hillsdale: Lawrence Earlbaum.

Cushman, P. (1990). Why the self is empty: Toward a historically situated psychology. American Psychologist, 45, 599-611.

Elias, N. (1994). A sociedade dos individuos. (V. Ribeiro, Trad.) Rio de Janeiro: Zahar. (Trabalho original publicado em 1987)

Fogel, A., Lyra, M. \& Valsiner, J. (1997). Dynamics and indeterminism in developmental and social processes. Hillsdale: Lawrence Erlbaum.

Ford, D. H. \& Lerner, R. M. (1992). Developmental systems theory. Newbury Park, CA: Sage.

Geertz, C. (1978) A Interpretação das culturas. (F. Wrobel, Trad.) Rio de Janeiro: Zahar. (Trabalho original publicado em 1973)

Gone, J. P., Miller, P. J. \& Rappaport, J. (1999). Conceptual self as normatively oriented: The suitability of past personal narrative for the study of cultural identity. Culture \& Psychology, 5, 371-398.

González Rey, F. (2002) Pesquisa qualitativa em psicologia: Rumos e desafios. (M.A.F. Silva, Trad.) São Paulo: Thomson. (Trabalho original publicado em 1999)

Hermans, H. (1996). Voicing the self: From information processing to dialogical interchange. Psychological Bulletin, 119, 31-50.

Hermans, H. (2001) Mixing and moving cultures require a dialogical self. Human-Development, 44, 24-28.

Hermans, H., Kempen, H. \& Van Loon, R. (1992) The dialogical self: Beyond individualism and rationalism. AmericanPsychologist, 4, 23-33.

Kohlberg, L. (1981). Essays on moral development. Vol 1: The philosophy of moral development. New York: Harper \& Row.

Kramer, S. (2003). A politica do pré-escolar no Brasil: A arte do disfarce. São Paulo: Cortez.

Kramer, S. \& Leite, M. I. (1996). Infância: fios e desafios da pesquisa. Campinas: Papirus.

Lawrence, J. \& Valsiner, J. (1993). Conceptual roots of internalization: From transmission to transformation. Human Development, 36 , 150-167.

Madureira, A. F. A. \& Branco, A. U. (2005). Construindo com o outro: uma perspectiva sociocultural construtivista do desenvolvimento humano. Em M. A. Dessen \& A. L. Costa Júnior (Orgs.), A ciência do desenvolvimento humano: tendências atuais e perspectivas futuras (pp. 90-109). Porto Alegre: Artmed.

Martins, L. \& Branco, A. U. (2001). Desenvolvimento moral: considerações teóricas a partir de uma Abordagem Sociocultural Construtivista. Psicologia: Teoria e Pesquisa, 17, 169-176.

McLaren, P. \& Giroux, H. (2000) Escrevendo das margens: geografias de identidade, pedagogia e poder. Em P. McLaren (Org.), Multiculturalismo revolucionário: pedagogia do dissenso para o novo milênio (pp. 25-49). Porto Alegre: Artmed.

Oppenheimer, L. (2001) Development of the self: A co-construtivist approach. Trabalho apresentado na X European Conference on Developmental Psychology, Uppsala, Suécia.

Palmieri, M. \& Branco, A. U. (2004). Cooperação, competição e individualismo em uma perspectiva sociocultural construtivista. Psicologia: Reflexão e Crítica, 2, 189-198.
Piaget, J. (1994). Ojuízo moral na criança. (E. Lenardon, Trad.) São Paulo: Summus. (Trabalho original publicado em 1932)

Rogoff, B. (1993). The cultural nature of human development. New York: Oxford University Press.

Sampson, E. E. (1985). The decentralization of identity: Toward a revised concept of personal and social order. American Psychologist, 11, 1203-1211.

Shweder, R.(1991). Cultural psychology: What is this? Em J. W. Stigler, R. A. Shweder \& G. Herdt (Orgs.), Cultural Psychology (pp. 1-43). Cambridge: Cambridge University Press.

Shweder, R. A. \& Much, N. C. (1987). Determinations of meaning: Discourse and moral socialization. Em W. M. Kurtines \& J. J. Gewirtz (Orgs), Moral development through social interaction (pp. 197-244). New York: Wiley.

Tomasello, M. (1999). The cultural origins of human cognition. Cambridge: Harvard University Press.

Valsiner, J. (1987). Culture and the development of children's actions. New York: Wiley.

Valsiner, J. (1989). Human development and culture: The social nature of personality and its study. Lexington, MA: Lexington Books.

Valsiner, J. (1994). Bidirecional cultural transmission and constructive sociogenesis. Em W. de Graaf \& R. Maier (Orgs.), Sociogenesis reexamined (pp.47-70). New York: Springer.

Valsiner, J. (1998). The guided mind. Cambridge: Harvard University Press.

Valsiner, J. (2000). Culture and human development: An introduction. London: Sage.

Valsiner J. (2007). Culture in minds and societies: Foundations of cultural psychology. New Delhi: Sage.

Valsiner, J., Branco, A. U. \& Dantas, C. M. (1997). Co-construction of human development: Heterogeneity within parental belief orientations. Em J. E. Grussec \& L. Kuczynski (Orgs.), Parenting and children internalization of values (pp. 283-304). New York: Wiley.

Valsiner, J. \& Cairns, R. (1992). Theoretical perspectives on conflict and development. Em C. V. Shantz \& W. W. Hartup (Orgs.), Conflict in child and adolescent development (pp. 15-35). Cambridge: Cambridge University Press.

Valsiner, J., \& Van der Veer, R. (2000). The social mind: Construction of the idea. Cambridge: Cambridge University Press.

Vigotski, L. S. (2001). A construção do pensamento e da linguagem. (P. Bezerra, Trad.) São Paulo: Martins Fontes. (Trabalho original publicado em 1934)

Watzlawick P., Beavin, J. H. \& Jackson, D. D. (1967). Pragmatics of human communication. New York: Norton.

Wertsch, J. V. (1991). Voices of mind. Cambridge: Harvard University Press.

Wertsch, J. V. (1998). Mind as action. New York: Oxford. 